\title{
COMPARABLE EFFICACY OF TERBINAFINE AND ITRACONAZOLE IN THE TREATMENT OF TINEA PEDIS
}

\author{
MD. ABDUL WAHAB ${ }^{1}$, MOHAMMAD JAMAL UDDIN ${ }^{2}$, BISWAS SHAHEEN HASSAN ${ }^{3}$, MD. ZAFRUL ISLAM $^{4}$, \\ ISHRAT BHUIYAN ${ }^{5}$, MOHAMMAD RAHMAT ULLAH SIDDIQUE ${ }^{6}$
}

\begin{abstract}
Background: Tinea pedis (athlet's foot) is the most common fungal infection. Relapse is common in tinea pedis and may be result of recurrence following inadequate treatment or reinfection.

Objective: To evaluate the comparable efficacy of terbinafine and itraconazole in the treatment of tinea pedis.

Methods: 120 patients of tinea pedis confirmed by KOH microscopy were included in the study. The study was carried out in three different Hospitals and Private Chambers for a period of 3 years from July 2006 to June 2009. Mean age of the patients was 40.28 10.23. The patients were devided into 2 equal group:A \& B. Group- A was given terbinafine $250 \mathrm{mg} /$ day and group- $B$ was given intraconazole $200 \mathrm{mg} /$ day for 2 weeks.

Results: Follow up 2 weeks after cessation of therapy revealed clinical and mycological cure of 93.3\% in terbinafine group and $86.6 \%$ in itraconazole group.

Conclusion: Efficacy analysis revealed that terbinafine is superior than itraconazole in the treatment of tinea pedis (P value 0.224).
\end{abstract}

Key words: Terbinafine, Itraconazole, Treatment outcome, Tinea pedis.

\section{Introduction}

Tinea pedis (Athlet's foot) is the most common fungal infection that causes scaling, flaking and itching of affected areas. Tinea pedis is contagious and can be passed through direct contact or contact with items such as shoes, stocking and shower or pool surfaces. There are several distinct forms encountered in clinical practice:

a. Interdigital type - toe web space infection in which the interdigital toe clefts become fissured, macerated and itchy and is the most common presentation of tinea pedis. The changes frequently recur endlessly following treatment.

b. Papulosquamous type - scaly papular lesions on dorsum of the feet and may also involved plantar aspect. c. Hyperkeratotic type - minute papules with well demarcated erythema on margin, fine white scaling and hyperkeratosis confined to heels, soles and lateral border of feet.

d. Vesico-bullous type - occurs particularly on the soles and sides of the feet. These may widespread and confluent leading to quite big blisters. The areas are generally extremely itchy.

e. Mixed type - combination of above presentation. ${ }^{1,2}$

Male are affected more than female and 20-50 years age group is commonly affected. Relapse is common in tinea pedis and may be the result of inadequate treatment or reinfection. ${ }^{3}$

There are many conventional treatments such as topical antifungal agent, which can take the form of

1. Associate Professor, Department of Dermatology \& Venereology, Bangabandhu Sheikh Mujib Medical University, Dhaka, Bangladesh.

2. Assistant Professor, Department of Dermatology \& Venereology, Bangabandhu Sheikh Mujib Medical University, Dhaka, Bangladesh.

3. MD (Dermatology) Student, Department of Dermatology \& Venereology, Bangabandhu Sheikh Mujib Medical University, Dhaka, Bangladesh.

4. Medical officer, Department of Dermatology \& Venereology, Bangabandhu Sheikh Mujib Medical University, Dhaka, Bangladesh.

5. Department of Dermatology \& Venereology, Bangabandhu Sheikh Mujib Medical University, Dhaka, Bangladesh.

6. Research Assistant, Department of Dermatology \& Venereology, Bangabandhu Sheikh Mujib Medical University, Dhaka, Bangladesh.

Bangladesh J Medicine 2010; 21 : 74-79 
spray, powder, cream, gel or lotion and oral medication as griseofulvin, fluconazole, itraconazole, terbinafine, ketoconazole etc. Topical therapy sometimes are effective but recurrence is more after stopping. ${ }^{4}$ There have been many reports on the therapeutic effects of oral terbinafine and itraconazole on tinea pedis. However till now no reports on these drugs have published in Bangladesh. So this study has been designed to evaluate the comparable efficacy of terbinafine and itraconazole in the treatment of tinea pedis.

\section{Patients and Methods}

Over a 3 year period from July 2006 to June 2009, 120 patients of tinea pedis aged 20-60 years were studied in the Department of Dermatology \& Venereology at Bangabandhu Sheikh Mujib Medical University, Combined Military Hospital and Shaheed Suhrawardy Hospital and 3 Private Chambers, Dhaka, Bangladesh. The cases were taken based on clinical feature and $\mathrm{KOH}$ examination. Routine hematological and $\mathrm{KOH}$ examination were done at the start of treatment and at 6 week follow up end point. 80 male and 40 female of whom, 40 had papulosquamous type, 38 had intertriginous type, 30 had hyperkeratotic type and 12 had mixed type. The patients were randomly devided into 2 equal groups. Group-A was given terbinafine $250 \mathrm{mg} /$ day and itraconazole $200 \mathrm{mg}$ /day in group-B for 2 weeks. All patients had given informed written consent. The patients were excluded from the study if they were pregnant, nursing mother, age below 20 and above 60 years, sensitivity to terbinafine and itraconazole, patients who used any other antifungal (topical/systemic) within a week before initiating this treatment, taking medications that could interfere with trial drugs and having serious systemic illness.

Outcome measures were evaluated weekly during treatment and 2 weeks after cessation of therapy and then the patients (those cured) were followed up for 3 years to see the relapse.

Cure means resolution of signs \& symptoms and -ve $\mathrm{KOH}$ microscopy.

Relapse means reappearance of signs and +ve $\mathrm{KOH}$ microscopy.
Demographic data of the patients and clinical findings and clinical response are summarized in table-I to V.

\section{Results}

120 patients (80 male and 40 female) of 20-60 years age group were included into this study. Mean age of the patients was $40.28 \pm 10.23$ (Table-I). The duration of the disease ranged from less than 3 months to more than 6 months. The mean duration in group-A was $4.21 \pm 2.14$ and in group-B was $4.83 \pm 2.77$. Maximum patients $(36.66 \%)$ in this study were in 3-6 months duration folllwed less than 3 months (35.83\%) in tableII. In our study papulosquamous type was more 40 (33.33\%) followed by intertrigenous 38 (31.66\%). Mixed type was least variant 12 (10\%) followed by hyperkeratotic 30 (25\%) (Table III). The rate of clinical and mycological cure was found in 56 (93.3\%) cases in Group A and $52(86.6 \%)$ in group- B at the follow up end point ( 6 weeks after starting treatment). In total treatment produced cure in 108 (90\%) and no cure in $12(10 \%)$ cases. The severity of the clinical signs and symptoms decreased from baseline to treatment end point and to the treatment end point to follow up end point in both group. The tolerability of study medication was rated good in almost all patients. The patients (those cured) were followed up for 3 years to see the relapse. At 1 year, $12.5 \%$ had a relapse, at 2 year, $16.07 \%$ had relapse and at 3 year, $17.86 \%$ had relapse in group-A and in group- B, 17.30\%, 21.15\%, 23.07\% had relapse at 1,2 , and 3 year respectively.

Table I

Age and Sex incidence $(N=120)$

\begin{tabular}{lccccc}
\hline Age in & \multicolumn{2}{c}{ Male } & & \multicolumn{2}{c}{ Female } \\
\cline { 2 - 3 } \cline { 5 - 6 } years & Number & Percentage & & Number & Percentage \\
\hline $20-30$ & 15 & 12.50 & & 08 & 6.66 \\
$31-40$ & 20 & 16.66 & & 10 & 8.33 \\
$41-50$ & 35 & 29.16 & & 18 & 15 \\
$51-60$ & 10 & 8.33 & & 04 & 3.33 \\
\hline Total & $\mathbf{8 0}$ & $\mathbf{6 6 . 6 6}$ & $\mathbf{4 0}$ & $\mathbf{3 3 . 3 3}$ \\
\hline
\end{tabular}

Mean age $40.28 \pm 10.23$

Table-II

Duration of the disease $(N=120)$

\begin{tabular}{|c|c|c|c|c|c|c|}
\hline \multirow[t]{2}{*}{ Duration in months } & \multicolumn{2}{|c|}{ Male } & \multicolumn{2}{|c|}{ Female } & \multicolumn{2}{|c|}{ Total } \\
\hline & Number & Percentage & Number & Percentage & Number & Percentage \\
\hline$<3$ months & 28 & 23.33 & 15 & 12.5 & 43 & 35.83 \\
\hline 3-6months & 30 & 25 & 14 & 11.66 & 44 & 36.66 \\
\hline$>6$ months & 22 & 18.33 & 11 & 9.16 & 33 & 27.5 \\
\hline Total & 80 & 66.66 & 40 & 33.33 & 120 & 100 \\
\hline
\end{tabular}


Table III

Clinical pattern of Tinea Pedis $(N=120)$

\begin{tabular}{lccc}
\hline Clinical pattern & Group A N=60 & Group B N=60 & Total N= 120 \\
\hline Papulosquamous & $20(33.33 \%)$ & $20(33.33 \%)$ & $40(33.33 \%)$ \\
Interginous & $19(31.66 \%)$ & $19(31.66 \%)$ & $38(31.66 \%)$ \\
Hyperkeratotic & $15(25 \%)$ & $15(25 \%)$ & $30(25.00 \%)$ \\
Mixed & $06(10 \%)$ & $06(10 \%)$ & $12(10.00 \%)$ \\
\hline Total & $60(100 \%)$ & $60(100 \%)$ & $120(100 \%)$ \\
\hline
\end{tabular}

Table IV

Clinical response in Tinea Pedis

\begin{tabular}{lcc}
\hline Clinical pattern & $\begin{array}{c}\text { Clinical response in Group A } \\
(\mathrm{N}=60)\end{array}$ & $\begin{array}{c}\text { Clinical response in Group B } \\
(\mathrm{N}=60)\end{array}$ \\
\hline Papulosquamous (20) & $20(100 \%)$ & $20(100 \%)$ \\
Interginous (19) & $19(100 \%)$ & $17(89.47 \%)$ \\
Hyperkeratotic (15) & $13(86.66 \%)$ & $12(80 \%)$ \\
Mixed (06) & $04(66.66 \%)$ & $03(50 \%)$ \\
\hline Total & $56(93.3 \%)$ & $52(86.6 \%)$ \\
\hline
\end{tabular}

Table V

Relapse of Tinea Pedis

\begin{tabular}{lcccccc}
\hline Clinical pattern & \multicolumn{2}{c}{ Group A Terbinafine $(\mathrm{N}=56)$} & \multicolumn{3}{c}{ Group B Itraconazole (N=52) } \\
& $1^{\text {st }}$ year & $2^{\text {nd }}$ year & $3^{\text {rd }}$ year & $1^{\text {st }}$ year & $2^{\text {nd }}$ year & $3^{\text {rd }}$ year \\
\hline Papulosquamous & 3 & 3 & 3 & 2 & 3 & 3 \\
Interginous & 2 & 2 & 3 & 3 & 3 & 4 \\
Hyperkeratotic & 2 & 3 & 3 & 3 & 4 & 4 \\
Mixed & 0 & 1 & 1 & 1 & 1 & 1 \\
\hline Total & $7(12.5 \%)$ & $9(16.07 \%)$ & $10(17.86 \%)$ & $9(17.30 \%)$ & $11(21.15 \%)$ & $12(23.07 \%)$ \\
\hline
\end{tabular}

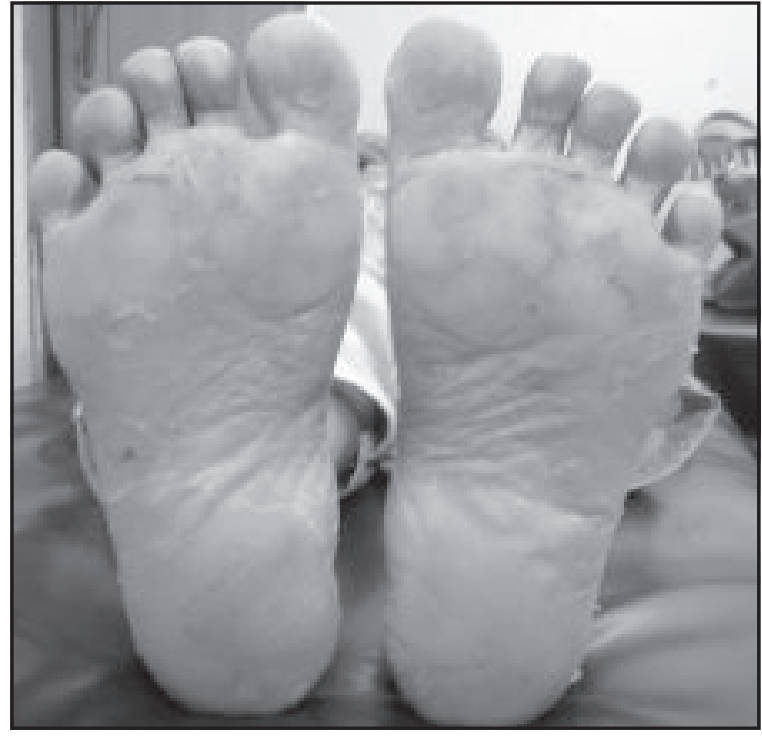

Fig 1a: Hyperkeratotic type (Before treatment)

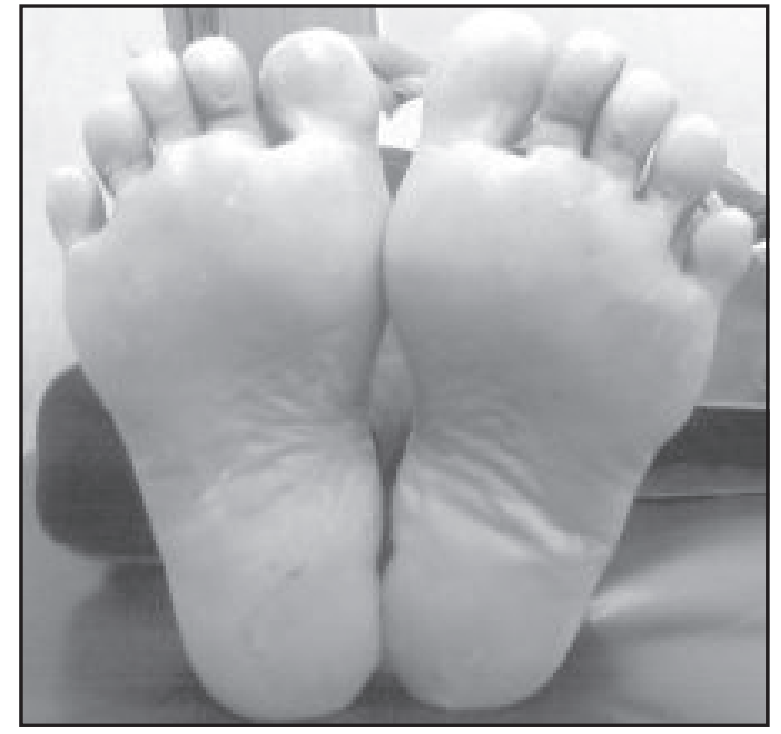

Fig 1b: Hyperkeratotic type (After treatment) 


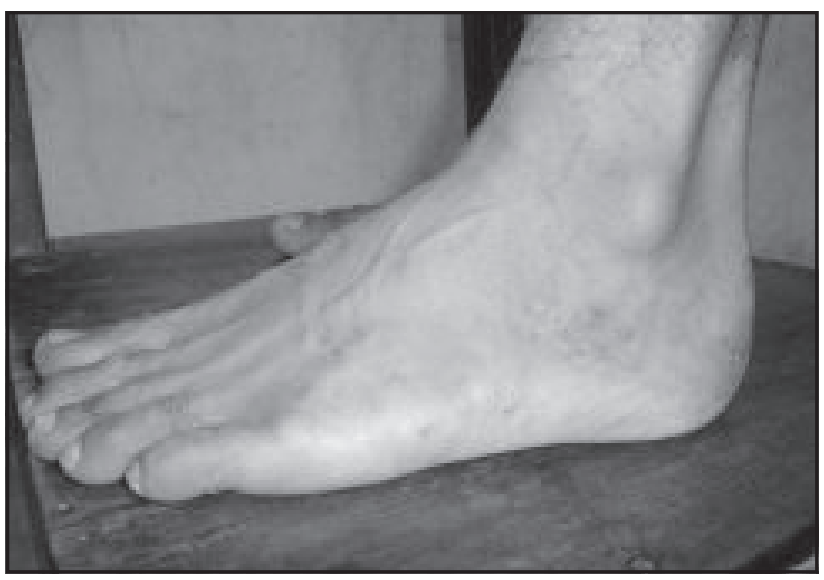

Fig 2a : Papulosquamous type (before treatment)

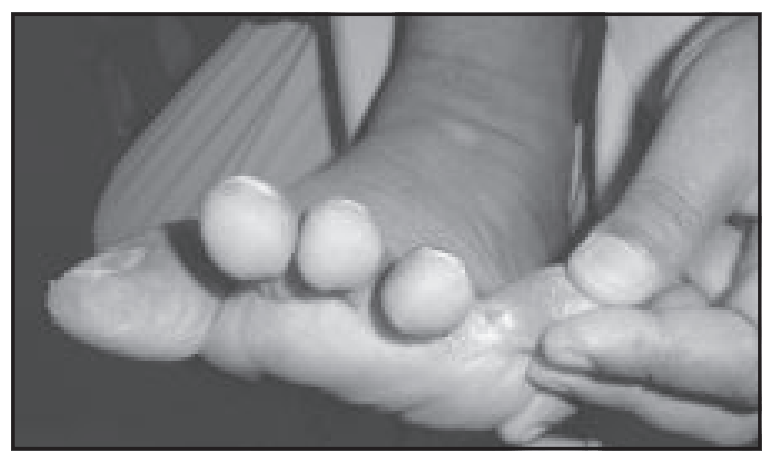

Fig 3a: Interdigital type (before treatment)

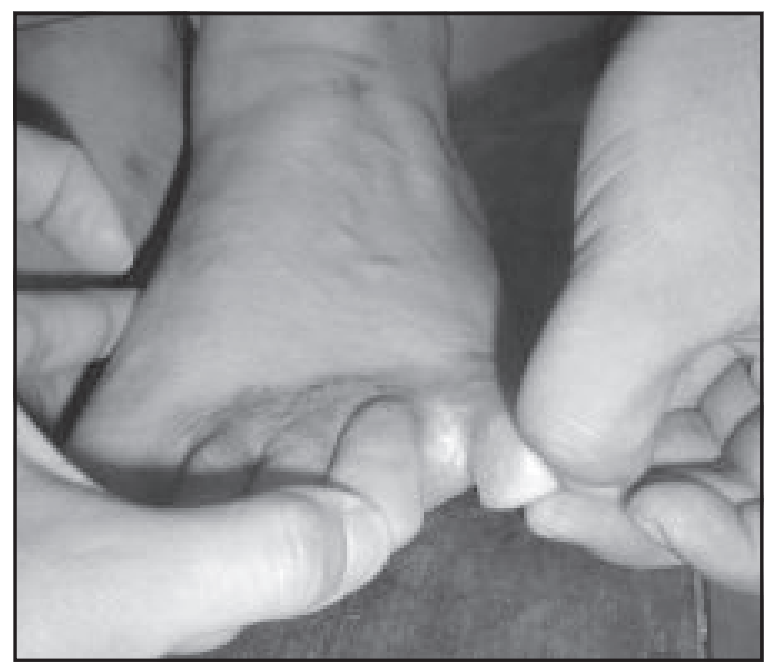

Fig 4a: Mixed type (before treatment)

\section{Discussion}

Tinea pedis is the most common fungal infection. It may last for a longtime and may come back after treatment. The affected areas are usually itchy, painful or asymptomatic. It ranges from mild to severe. They may persist or recur but they generally respond to treatment. Longterm medication and preventive

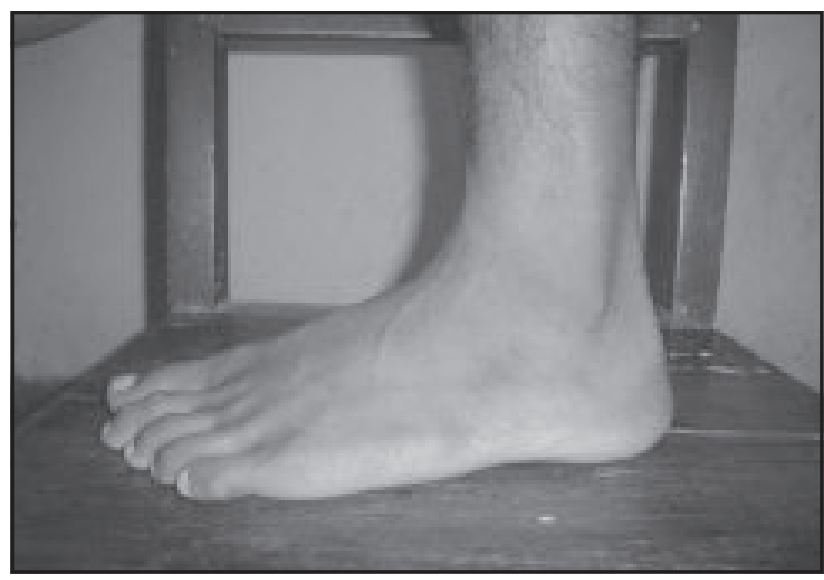

Fig 2b : Papulosquamous type (after treatment)

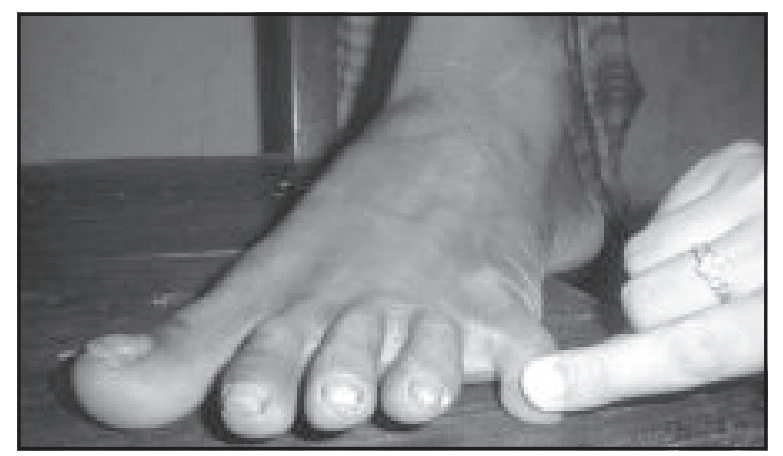

Fig 3b: Interdigital type (after treatment)

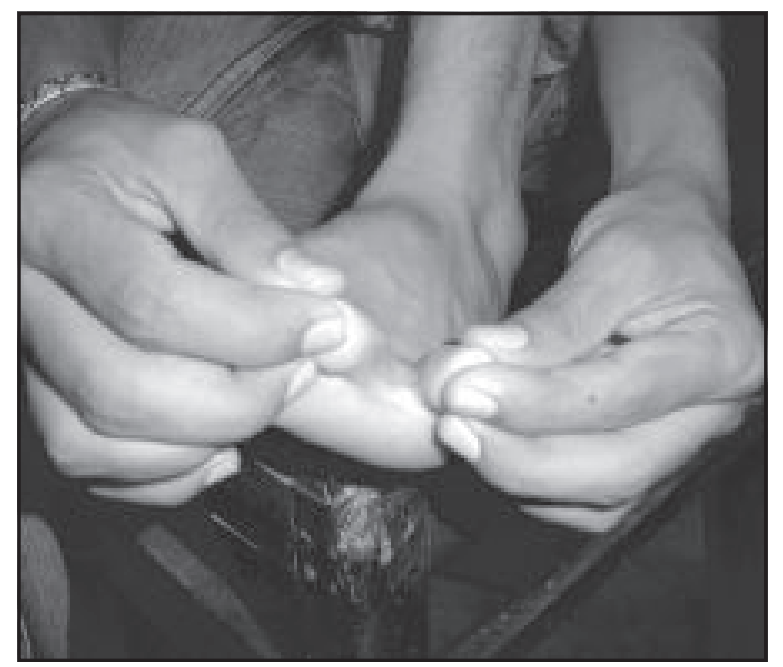

Fig 4b: Mixed type (after treatment)

measures may be needed. There are several forms of tinea pedis such as papulosquamous, hyperkeratotic, intertriginous, vesico-bullous, mixed type etc. ${ }^{1,3}$

In this study, we have taken papulosquamous type, intertriginous type, hyperkeratotic type and mixed type in both the group A and B. Group-A was given terbinafine $250 \mathrm{mg}$ daily and intraconazole $200 \mathrm{mg}$ 
daily in group-B for 2 weeks. Terbinafine is a synthetic allaylamine, inhibits ergosterol synthesis by inhibiting squalene epoxidase. It is known that accumulation has a biocidal effect on dermatophyte. In short, terbinafine has both mycostatical and biocidal effects on dermatophyte in general. The effectiveness of itraconazole can be attributed to its high tissue affinity and persistence in the stratum corneum for upto 4 weeks after discontinuation of therapy. ${ }^{2}$

In the present study total 120 patients were involved. Male $80(66.66 \%)$ were predominant in the study than female $40(33.33 \%)$ which is consistent with other study done by Lachapelle JM et al. ${ }^{4}$ The age of the study population ranged from 20-60 years and maximum patients in our study were in 41-50 years age group $53(44.16 \%)$ followed by $31-40$ years age group $30(25 \%)$ which is differing from other study done by Wishart J.M. ${ }^{5}$ In this study, the duration of the disease were less than 3 months to more than 6 months, we found maximum number of patients were 3-6 months duration 44 (36.66\%) followed by less than 3 months duration $43(35.83 \%)$. This findings also is differing from other study done by Gupta A K et al. ${ }^{6}$ In this study, most common clinical varients was found papulosquamous 40 (33.33\%) followed by intertriginous $38(31.66 \%)$ which is also differing from other study, where they found intertriginous type was most commonly found. ${ }^{7}$

Two groups of people were studied: guoup-A with terbenafine $250 \mathrm{mg}$ daily and group-B with itraconazole $200 \mathrm{mg}$ daily for 14 days. We evaluated weekly during treatment and 2 weeks after cessation of therapy. The clinical response was rated as cure 108 (90\%) and no cure 12 (10\%). The clinical response was found in papulosquamous type: 20/20, 20/20; intertriginous type: 19/19, 17/19; hyperkeratotic type: 13/15, 12/ 15; mixed type: 04/06, 03/06 in group-A and group-B respectively. In average $93.3 \%$ clinical inprovement was found in group-A and $86.6 \%$ in group-B.

Keysen De et al. ${ }^{8}$ compared 2 weeks of terbinafine at $250 \mathrm{mg} /$ day to 2 weeks of itraconazole at $100 \mathrm{mg} /$ day in tinea pedis, they found terbinafine superior to itraconazole for clinical cure (94\% vs $72.4 \%)$.Iwao Takinchi et al. ${ }^{9}$ studied and found $89.3 \%$ improvement of tinea pedis with 1 week treatment with $250 \mathrm{mg}$ terbinafine. A study done by Barnatson et al. ${ }^{10}$ and found $72 \%$ improvement with $250 \mathrm{mg}$ of terbinafine for 1 week in tinea pedis.

Hay et al. ${ }^{11}$ compared 2 weeks of oral terbinafine (250mg/day) with 4 weeks of oral itraconazole (100mg/ day) and cure of terbinafine group was $78 \%$ in tinea pedis.
Kagawa $\mathrm{S}^{12}$ treated 184 patients with oral terbinafine (250mg/day) for 2 weeks and reported a clinical cure of $94 \%$. Using similar regimen, White et al. ${ }^{13}$ treated tinea pedis and found $86 \%$ improvement.

J. Schuller et al. ${ }^{14}$ studied and found $63 \%$ improvement with $400 \mathrm{mg} /$ day for 1 week with itraconazole and $75 \%$ in $100 \mathrm{mg} /$ day with itraconazole for 1 month at the end of 6 weeks follow up period.

Gupta, A. K. et al. ${ }^{15}$ found $81 \%$ improvement of tinea pedis with $400 \mathrm{mg} /$ day for 1 week and $75 \%$ with $100 \mathrm{mg}$ / day for 4 weeks with itraconazole at the end of 6 weeks follow up period.

E. Van Hecka et al. ${ }^{16}$ experienced $85 \%$ cure rate with $100 \mathrm{mg} /$ day of itraconazole in tinea pedis for 1 month after 2 weeks of end of treatment.

E.M. Difonzo et al. ${ }^{17}$ studied and concluded $82.2 \%$ cured with itraconazole $100 \mathrm{mg} /$ day for 30 days in tinea pedis.

R. Savin. ${ }^{18}$ treated tinea pedis with $125 \mathrm{mg}$ of terbinafine twice daily for 6 weeks and found $88 \%$ improvement after 2 weeks follow up period.

Tausch I et al. ${ }^{19}$ studied with a course of itraconazole $200 \mathrm{mg}$ twice daily for 07 days and terbinafine 250mg daily for 14 days in tinea pedis and revealed clinical improvement $80 \%$ in terbinafine group and $79 \%$ intraconazole group after follow up period of 6 weeks end point. So in comparing the other studies with our study revealed some of the studies are almost consistent with our result and some of the studies are slightly differing from our study.

The issue of recurrence versus reinfection must always be considered in patients with relapse. Our findings of $12.5 \%$ had relapse at 1 year, $16.07 \%$ at 2 year and $17.86 \%$ at 3 year in group A and in group B at 1 year, 2 year and 3 year had relapse $17.30 \%$, $21.15 \%$ and $23.07 \%$ respectively suggest that reinfection is more likely than recurrence.

\section{References:}

1. Schafer-Korting M, Schoellmann C, Korting HC. Fungicidal activity plus reservoir effect allow short course with TBF in Tinea Pedis. J Pharmacol biophysic Research 2008;21 (4): 203-210.

2. Kikuchi I, Tanuma H, Morimoto K, Kawana S. Usefulness and pharmacokinetic study of oral terbinafine for hyperkeratotic type tinea pedis. Mycoses 2007; 51 (1): 7-13.

3. Mc Clellan KJ, Wiseman LR, Marktiam A. Terbinafine: An update of its use in superficial mycoses. Drugs 1999; 58 (1): 179-202.

4. Lachapelle JM, De Doncker P, Tennesfedt D, 
Cauwenbugh G, Jansson PA. Itraconazole compared with griseofulvin in the treatment of tinea pedis/ mannum. Dermatol 1992; 184: 45-50.

5. Wishart JM. A double blind study of itraconazole vs griseofulvin in patients with tinea pedis and tinea manus. N Z Med J 1994; 107:126-8.

6. Gupta AK, Sauder DN, Shear NH. Antifungal agent: an overview: Part I. J Am Acad Dermatol. 1994; 30 (Spt I): 677-98.

7. Philpot, C.M. Some aspects of the epidemiology of tinea. Mycopathologica 1977; 62: 3-13.

8. Keysen P De, Backer M De, Massart D L, Westchinck $\mathrm{K}$ J. Two week oral treatment of tinea pedis, comparing terbinafine $(250 \mathrm{mg} /$ day $)$ with itraconazole (100 mg/day): a double-blind, multicentric study. Brit J Dermatol 1994; 130 (suppl 43): 22-25.

9. Takinchi I, Morshita N, Hamaguchi T, Ninomiya J, Hisuchi R. Treatment outcome and relapse with short-term oral trebinafine in tinea pedis. Jpn $\mathrm{J}$ Med Mycol 2005; 46: 285-289.

10. Barnetson R StC, Marley J, Bullen M, Brookman S, Cowen P, Ellis D and Williams T. Comparison of one week of oral terbinafine $(250 \mathrm{mg} /$ day) with four weeks of treatment with clotrimazole $1 \%$ cream in interdigital tinea pedis. Brit. J. dermatol. 1998; 139: 675-678.

11. Hay RJ, Mc Gregor JM, White J, Ryatt KS, Zieglu C, Clayton YM. A comparison of 2 weeks of terbinafine $250 \mathrm{mg} /$ day with 4 weeks of itraconazole $100 \mathrm{mg} /$ day in planter-type tinea pedis. Brit. J. Dermatol. 1995; 132: 604-608.
12. Kagawa S: Prognosis in tinea pedis. Jpn J Med Mycol 1968; 9: 109-114.

13. White JE, Perkins PJ and Evans EGV: Successive 2 weeks treatment with terbinafine (lamisil) for moccasin tinea pedis and tinea mannum. Brit $\mathrm{J}$ Dermatol. 1991; 125: 260-62.

14. Schuller J, Remme JJ, Rampun FHJ, Van Neer FCJ. Itraconazole in the treatment of tinea pedis and tinea manus: comparison of two treatment schedule. Mycoses 2008; 41 (11-12): 515-520.

15. Gupta AK, De Doncker P, Heremans A et al. Itraconazole for the treatment of tinea pedis: a dosage of $400 \mathrm{mg} /$ day given for 1 week is similar to efficacy to 100 or $200 \mathrm{mg} /$ day given for 2-4 week. J Am Acad Dermatol. 1997; 36: 789-792.

16. Van Hecke E, Van Cutsem J. Double blind comparison of itaconazole with griseofulvin in the treatment of tinea pedis and tinea manuum. Mycoses 2009; 31 (12): 641-649.

17. Difonzo EM, Papini M, Cilli P, Calandra P, Panconesi E. A double blind comparison of itraconazole and fluconazole in tinea pedis and tinea manuum. J European Acad Dermatol Venereol 2006; 4 (2): 148-152.

18. R. Savin. Successful treatment of chronic tinea pedis with terbinafine (lamisil). Clin Experimen Dermatol 2006; 14(2): 116-119.

19. Tousch I, Decroix J, Gwiezdzinski Z, Urtanowski S, Batan E, Ziarkiewicz M, Levy G, Del Palacio A. Short term itraconazole versus terbinafine in the treatment of tinea pedis and manum. Int $\mathrm{J}$ Dermatol 1998; 37 (2): 140-2. 